\title{
Outbreak of Infantile Gastro-enteritis Caused by Escherichia coli $\mathrm{O} 114$
}

S. I. JACOBS, A. HOLZEL, B. WOLMAN, J. H. KEEN, V. MILLER, JOAN TAYLOR, and R. J. GROSS

From the Departments of Pathology and Paediatrics, Booth Hall Children's Hospital, Manchester; and the Salmonella Reference Laboratory, Central Public Health Laboratory, London

Jacobs, S. I., Holzel, A., Wolman, B., Keen, J. H., Miller, V., Taylor, J., and Gross, R. J. (1970). Archives of Disease in Childhood, 45, 656. An outbreak of infantile gastro-enteritis caused by Escherichia coli 0114. An outbreak of infantile gastro-enteritis occurred at Booth Hall Children's Hospital as part of a general incident in north-western England, caused by Esch. coli $0114 \mathrm{~K} 90 \mathrm{H} 2$.

The organism, which could not be identified with routinely used antisera, caused an unusually prolonged illness after an insidious onset, and was characterized by severe vomiting, together with the passage of very watery stools which became mucuslike and which had a distinctive smell. 29 children were affected and 20 required intravenous feeding for a mean period of 10 days. 7 children died late in the illness, but all were young and debilitated by other acquired or congenital anomalies. Sugar intolerance was prominent, and there was difficulty in returning the children to their routine formulae. Gentamicin and colistin sulphate may have had some effect in reducing the mortality caused by the illness.

Liver function abnormality was common, suggesting that Esch.coli $\mathrm{O} 114 \mathrm{might}$ have produced a substance with widespread visceral effects.

In December 1968 an unusual form of infantile gastro-enteritis was first seen in the Manchester area (Lancet, 1969) and continued into the spring of 1969. The illness was very severe, had a prolonged course, and was associated with a high mortality. It was caused by Escherichia coli $\mathrm{O} 114 \mathrm{~K} 90 \mathrm{H} 2$ (Jacobs, 1969).

Esch. coli $\mathrm{O} 114 \mathrm{~K} 90 \mathrm{H} 2$ was previously implicated as a cause of infantile gastro-enteritis in Birmingham from December 1951 to January 1954 (Rogers and Cracknell, 1956) and the same Esch. coli serotype was responsible for another outbreak in the Munich area in 1958 (Linzenmeier, 1960). Four cases of infantile diarrhoea due to Esch. coli $\mathrm{O} 114$ were noted in London between 1954 and 1956, but all these organisms possessed flagellar antigens different from the one found in the present outbreak (Charter, 1956). Two strains of Esch. coli O114K $90 \mathrm{H} 32 \mathrm{had}$ been isolated from calves with scours in 1950, a serotype grown from the sporadic cases of human illness examined by Charter.

Though some of the patients seen in Birmingham

Received 14 April 1970. were severely ill and required intravenous therapy, none died, nor was their disease pattern unusual. Similarly, babies suffering from gastro-enteritis caused by Esch. coli O114 were treated in London in mid-1968 and early 1969 (British Medical Journal, 1969; Valman and Wilmers, 1969), but there is no indication that their illness took a distinctive clinical course.

\section{Clinical Features of Disease During Man- chester Outbreak}

Gastro-enteritis caused by Esch. coli. 0114 differed from the commonly encountered pattern of disease in several of its manifestations.

Severity of illness and age incidence. Esch. coli $\mathrm{O} 114$ was isolated from 29 patients under the age of 2 years, and 21 required intravenous fluid treatment. 3 patients were symptomless excretors of the organism. The illness was most serious in very young children: all the 15 children under the age of 2 months required intravenous therapy, and 6 of the 7 deaths occurred in this age-group. The 

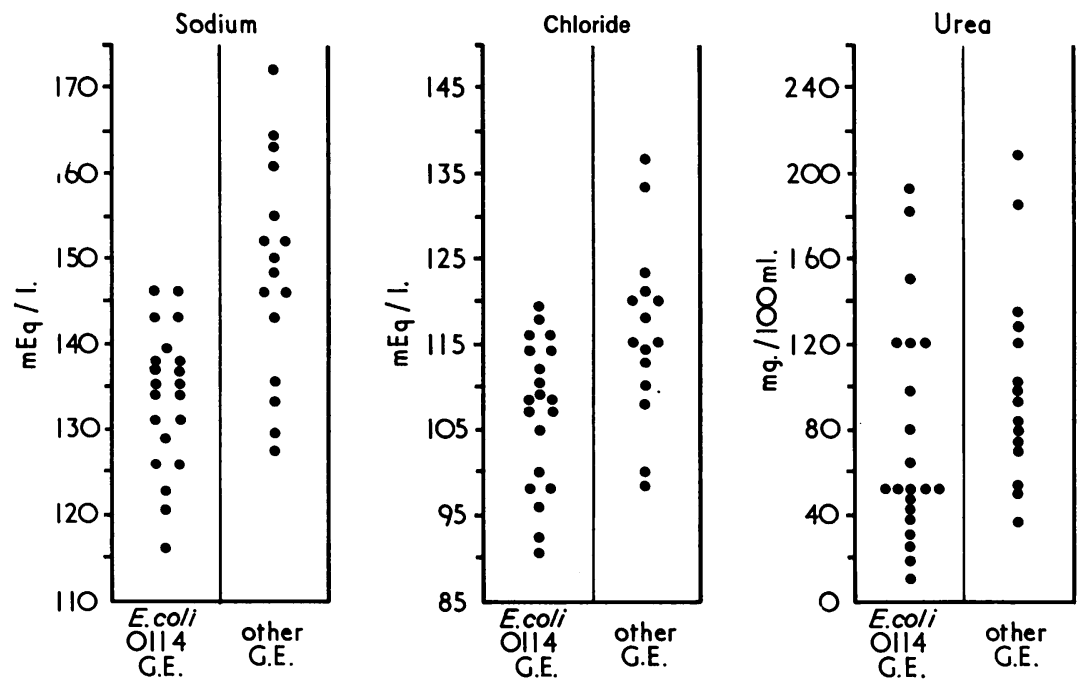

FIG.-The admission serum sodium, chloride and blood urea levels in children with gastro-enteritis.

oldest child to die was a boy aged 4 months who was maintained by parenteral feeding for 30 days.

Onset. The illness, before the infant's admission to hospital, was described as starting with mild diarrhoea, the number of stools gradually increasing over the course of 2 or 3 days, with vomiting becoming a regular accompaniment.

The time that elapsed between the onset of symptoms of gastro-enteritis and the institution of intravenous therapy among 18 of the 21 patients infected by Esch. coli O114 was much longer than that observed in 17 children of similar age requiring intravenous therapy for gastro-enteritis in the period December 1967 to March 1968. These latter children are presumed not to have been infected with this specific organism and may be regarded as controls. 9 of the 18 children suffering from Esch. coli $\mathrm{O} 114$ gastro-enteritis were ill for more than 3 days before the start of intravenous rehydration and 4 to 6 days elapsed in 5 instances. By contrast, a delay of more than 2 days was seen only once among the controls.

Electrolyte state on admission. The serum sodium, chloride, and blood urea levels found on admission among the 21 patients suffering from Esch. coli $\mathrm{O} 114$ gastro-enteritis were compared with those observed in 16 of the 17 patients used as the control group (Fig.). None of the children with Esch. coli 0114 gastro-enteritis was hypernatraemic on admission, whereas 9 of the 16 patients with typical gastro-enteritis had serum sodium levels over
$146 \mathrm{mEq} / \mathrm{l}$. The mean serum sodium levels for the two groups on entering hospital were 132 and $149 \mathrm{mEq} / \mathrm{l}$., respectively. Among the babies suffering from Esch. coli 0114 gastro-enteritis the mean values for serum chloride and blood urea were $107 \mathrm{mEq} / \mathrm{l}$. and $74 \mathrm{mg} . / 100 \mathrm{ml}$. In the control group, these admission levels were $117 \mathrm{mEq} / 1$. and $101 \mathrm{mg} . / 100 \mathrm{ml}$.

These biochemical findings support the clinical impression that Esch. coli 0114 gastro-enteritis was insidious in its onset, lacking the explosive onset with severe and rapid disturbance of the body's electrolyte balance that is usually seen in severe gastro-enteritis.

Course of illness. Among the children with Esch. coli $\mathrm{O} 114$ gastro-enteritis who required intravenous therapy, vomiting was a prominent and persistent symptom. It was noted in all the babies on their second day in hospital and it was still occurring in half of them 1 week after their admission. Among the control group less than half were vomiting after 48 hours in hospital and beyond this time the symptom was seen only sporadically.

Similarly, the children suffering from Esch. coli O114 gastro-enteritis had an unusually intractable form of diarrhoea. Thus, the pattern of bowel action of the majority of the control group of children had returned to normal by the third day of their stay in hospital, whereas all the specifically infected group were affected by diarrhoea for a much longer time. The faeces of the babies with Esch. coli O114 gastroenteritis were initially so watery that they could 
scarcely be distinguished from urine. Later they consisted entirely of mucus and had a characteristic foetid smell unlike anything previously associated with infantile diarrhoea, and which pervaded the entire cubicle.

Feeding difficulties. In babies suffering from Esch. coli $\mathrm{O} 114$ gastro-enteritis it was necessary to maintain the children by parenteral feeding for prolonged periods, because any attempt to give nourishment by mouth precipitated a rapid return of diarrhoea and vomiting, or severely exacerbated these symptoms.

None of the 21 children who developed Esch. coli 0114 gastro-enteritis and required intravenous support was treated in this way for less than 3 days and only 8 could dispense with this form of therapy in under 1 week. The mean length of time parenteral alimentation was maintained was $10 \cdot 2$ days and the maximum period was 30 days. When death occurred, this was a late event and supervened, on average, $14 \cdot 4$ days after the beginning of intravenous feeding. These findings contrast markedly with those observed in the control group of 17 children who required intravenous therapy, amongst whom the infusion was never maintained for more than 3 days (mean 1.6 days) with 4 of the 5 deaths occurring during the child's first day of hospital treatment.

Though a child with Esch. coli 0114 gastroenteritis frequently required prolonged intravenous therapy, there was little difficulty in maintaining normal electrolyte and urea levels in the blood even in those cases which finally proved fatal.

Prognosis. A bad prognosis was indicated by the development of any of three signs-gastro- intestinal haemorrhage, jaundice, and anasarca and effusions in the serous cavities.

Four of the 7 patients who died, vomited fresh blood or passed melaena stools before death, and evidence of alimentary tract bleeding was found in two others at necropsy. Amongst these children with ante-mortem haemorrhage, the bleeding began to occur $6,4,3$, and 2 days, respectively, before death. The blood coagulation system was normal in 2 of these infants as measured by the plasma clotting time, the prothrombin time, the kaolin cephalin time, the thrombin calcium time, and the fibrinogen titre. No haemorrhage was observed in any child with Esch. coli $\mathrm{O} 114$ gastro-enteritis who survived.

Jaundice was apparent in 5 of the 7 children with Esch. coli $\mathrm{O} 114$ gastro-enteritis who died. It was not seen in any baby who recovered. The Table records the results of the tests of liver function in 10 patients with Esch. coli O114 infantile diarrhoea. These tended to be more seriously deranged in the fatal cases than in the survivors. Some abnormalities in these tests were found very early in the course of the disease even in children who recovered. Thus, the serum transaminase levels were raised in patients $A$ and $E$ by the fourth day of illness. Similarly, the changes persisted after the cessation of intravenous therapy, for an SGOT level of 76 IU was demonstrated in baby B 3 weeks beyond the end of parenteral feeding. Patients $D$ and $G$ retained biochemical changes 9 and 7 days, respectively, after the children had returned to an oral feeding regimen.

All the children who died were oedematous. This oedema developed despite the addition of theoretically adequate amounts of amino acid solu-

TABLE

Liver Function Test Results in Children with Esch. coli O114 Gastro-enteritis

\begin{tabular}{|c|c|c|c|c|c|c|c|c|c|c|c|c|c|c|c|c|c|}
\hline \multirow{2}{*}{$\begin{array}{l}\text { Outcome of Illness } \\
\text { Patient }\end{array}$} & \multicolumn{10}{|c|}{ Recovered } & \multicolumn{7}{|c|}{ Died } \\
\hline & $\mathbf{A}$ & $\mathbf{B}$ & $\mathrm{C}$ & I & & & $\mathbf{E}$ & & F & G & $\mathbf{x}$ & $\mathbf{Y}$ & & & $\mathbf{Z}$ & & \\
\hline Day of test & 4 & 27 & 9 & 8 & 25 & 4 & 9 & 15 & 16 & 24 & 8 & 10 & 3 & 16 & 21 & 25 & 26 \\
\hline $\begin{array}{l}\text { Direct Van den Bergh } \\
\text { reaction } \\
\text { Serum total bilirubin } \\
\text { (mg./100 ml.) } \\
\text { Serum alkaline } \\
\text { phosphatase (KA } \\
\text { units) } \\
\text { Thymol turbidity units } \\
\text { SGOT IU } \\
\text { SGPT IU }\end{array}$ & $\begin{array}{l}\text { Neg. } \\
0 \cdot 1 \\
\\
8 \cdot 4 \\
1 \\
127 \\
210\end{array}$ & $\begin{array}{l}- \\
\overline{76} \\
32\end{array}$ & $\begin{array}{r} \pm \\
0 \cdot 7 \\
\\
14 \\
1 \\
16 \\
135\end{array}$ & $\begin{array}{l}\text { Neg. } \\
0 \cdot 1 \\
10 \cdot 8 \\
1 \\
56 \\
35\end{array}$ & $\begin{array}{l}- \\
- \\
85 \\
40\end{array}$ & $\begin{array}{c}+ \\
0 \cdot 7 \\
14 \cdot 0 \\
1 \\
55 \\
75\end{array}$ & $\begin{array}{c}+ \\
1 \cdot 42 \\
12 \cdot 8 \\
1 \\
110 \\
120\end{array}$ & $\begin{array}{c} \pm \\
0 \cdot 7 \\
\\
13 \cdot 2 \\
1 \\
56 \\
28\end{array}$ & $\begin{array}{l}- \\
- \\
52 \\
27\end{array}$ & $\begin{array}{l}- \\
\overline{70} \\
20\end{array}$ & $\begin{array}{c}+ \\
7 \cdot 8 \\
29 \cdot 2 \\
1 \\
- \\
-\end{array}$ & $\begin{array}{c}- \\
6 \cdot 37\end{array}$ & $\begin{array}{c}\text { Neg. } \\
0 \cdot 1 \\
\\
12 \cdot 8 \\
1 \\
35 \\
35\end{array}$ & $\begin{array}{c}++ \\
3 \cdot 54 \\
\\
14 \cdot 8 \\
1 \\
280 \\
180\end{array}$ & $\begin{array}{c}- \\
14 \cdot 9 \\
- \\
\overline{200} \\
170\end{array}$ & $\begin{array}{c}++ \\
10 \cdot 6 \\
11 \cdot 2 \\
1 \\
110 \\
120\end{array}$ & $\begin{array}{l}- \\
8 \cdot 5 \\
- \\
- \\
-\end{array}$ \\
\hline
\end{tabular}

$-=$ Note done. 


\section{Outbreak of Infantile Gastro-enteritis Caused by Escherichia coli 0114}

tions and multivitamin preparations to their intravenous infusions. Plasma was also given to restore the depleted protein stores. At his death baby $Z$ was found to have a total serum protein level of $5.25 \mathrm{~g}$. $/ 100 \mathrm{ml}$. of which $3.5 \mathrm{~g}$. was albumin. Despite these normal protein values, at necropsy $165 \mathrm{ml}$. clear yellow fluid was found in his serous sacs, the majority being contained in the peritoneal cavity.

Antibiotic treatment. 12 of the 14 children treated with either gentamicin or colistin sulphate survived, but, in contrast, only 2 of the 7 infants who did not receive these antibiotics recovered.

However, it must be noted that these findings are not necessarily proof of the value of these antibiotics, for a number of the fatal cases occurred early in the outbreak, while many of the recoveries tended to be patients seen later in the year. Further, some of the treated infants received gentamicin and colistin during the course of their illness and not ab initio. Hence, they could partially consist of a self-selecting group who would have recovered even if these drugs had not been given.

Management of oral feeding. In the treatment of this prolonged illness the clinical impression was formed that the most successful means of reintroducing the children to oral feeding after intravenous infusion was $5 \%$ fructose in $N / 5$ saline.

This carbohydrate could be tolerated when other mono- and disaccharide and amino acid solutions provoked a rapid return of vomiting and diarrhoea. Lactose-containing preparations were particularly prone to cause an exacerbation of the child's symptoms and the apparent intolerance to this substance persisted for the longest period.

Attempts were made to perform lactose tolerance tests on 3 children who had seemingly recovered. Two vomited the loading dose of carbohydrate immediately and the tests were abandoned. The third child collapsed with profuse diarrhoea and vomiting during the test, and feeding by the intravenous route had to be restarted. Chromatographic examination of the faeces showed the presence of sugar, but the significance of this was doubtful because all the babies were subject to considerable intestinal hurry.

\section{Post-mortem Findings}

A post-mortem examination was performed on all the patients who died, and viable Esch. coli 0114 was recovered from the bowel of 6 of the 7 children at this time, even though they had been ill for a considerable period before their death.

The babies were anaemic and very oedematous. Clear yellow or orange fluid was found in every patient in all the serous cavities, being most copious in the peritoneum, where it ranged in amount from 15-125 ml. The pleural cavities contained about $10 \mathrm{ml}$. each and there was a similar quantity in the pericardium.

Large quantities of altered blood were found in 6 of the 7 cases along the entire length of the alimentary tract. This had originated from superficial gastric erosions. The mucosal pattern of the stomach was flattened as were the circular folds of the small intestine. The mucosa of the bowel was oedematous but no significant ulceration was found.

Jaundice was present in 5 of the 7 children, the liver being enlarged in all 7. Despite the generally wasted condition of the child, the liver weight was about twice that expected for the child's age. On microscopy, the liver was congested, infiltrated with fat and showed patchy necrosis.

The thymus never weighed more than one-fifth of the value accepted as normal. It, and the other reticulo-endothelial organs microscopically showed severe lymphoid depletion. The kidneys of the children were congested and on histological examination showed severe tubular cell swelling.

Major congenital anomalies were found in 2 children (spina bifida; repaired oesophageal atresia); one child had Down's syndrome (21-22/13-15 chromosomal translocation); and other infective complications were seen in 3 of the 4 remaining children (monilial pyelonephritis; staphylococcal septicaemia; bronchopneumonia). Thus, the specific infection can only be said to have played some part in causing the death of a group of debilitated children, and its exact role in this respect is problematic.

\section{Microbiological Findings}

A routine admission screening programme of faecal specimens was in operation before the outbreak began in order to discover patients carrying the common enteropathogenic Esch. coli serotypes, Salmonella and Shigella species and viruses. In January 1969 routine examination of throat swabs to isolate Mycoplasma sp. was instituted to eliminate the possibility that very young babies were reacting clinically in a bizarre manner to such organisms, for 2 older children had presented with primary atypical pneumonia.

The basis of the methods used to isolate these micro-organisms was as follows. 
Enteropathogenic Esch. coli: Plating onto McConkey and horse blood agar and examination of the Esch. coli growth with antisera prepared against the 9 most commonly encountered enteropathogenic serotypes, namely Esch. coli O26, O55, O86, O111, O119, O125, O126, O127, and 0128.

None of these antisera would identify Esch. coli 0114 or assist in differentiating it from normal non-enteropathogenic serotypes, but the techniques used were clearly satisfactory, for in 1969 this hospital reported to the Central Epidemiological Research Laboratory the isolation of 84 strains of enteropathogenic Esch. coli excluding type O114. The total of such organisms notified throughout England and Wales in 1969 was 5,147 (British Medical Journal, 1970). Therefore, this general children's hospital, with its daily average bed occupancy of 68 babies under 2 years old, contributed $1.5 \%$ of the entire national analysable total.

Salmonella and Shigella sp: Primary plating onto desoxycholate citrate agar, enrichment in selenite $F$ broth and replating on to desoxycholate citrate agar.

Viruses: Routine inoculation of either or both HeLa or Hep 2 cell lines, rhesus or cynomolgus monkey kidney cells, and the WI 38 line.

Mycoplasma sp: Inoculation of throat swabs on to a slightly modified enriched selective PPLO formula, described by Cruickshank (1965), and into a modification of Kraybill and Crawford's (1965) medium with subsequent plating on to Cruickshank's PPLO agar. Serum cold agglutinins were sought by the method recommended by Cruickshank (1965).

In order to determine whether a single Esch. coli serotype was common to a number of babies, faeces were collected from 3 infants with enteritis who had not been ill for more than 2 days and who had not received antibiotic therapy. No pathogen identifiable by the current regimen had been isolated from these specimens. Five representative colonies were selected from each McConkey plate for more detailed study by the Salmonella Reference Laboratory.

The Esch. coli serotypes found in these specimens were as follows:

Patient A: Esch. coli $\mathrm{O} 15 \mathrm{~K}$ ?H1 and O114K90H2.

Patient B: Esch. coli O44K ?H18 and O114K90H2.

Patient C: Esch. coli O4K12H2 and O44K ?H18.

Both Esch. coli $\mathrm{O} 44$ and $\mathrm{O} 114$ have been isolated from outbreaks of infantile enteritis, and it was not until cultures from further patients were examined that it became clear that Esch. coli 0114 was the important causal agent in this outbreak and was grown from the majority of patients.

Sensitivity tests on the organism were carried out using the disc diffusion method on nutrient agar, apart from those in which the effects of sulphonamides and trimethoprim were being examined. In these instances lysed blood agar was employed together with a light inoculum. All the antibiotic discs were manufactured by Mast Laboratories apart from trimethoprim and sulphamethoxazole, alone and in combination, which were obtained from Oxoid Ltd.
The organism was found to be resistant to ampicillin $(25 \mu \mathrm{g}$.$) , carbenicillin (100 \mu \mathrm{g}$.$) , cephaloridine (25 \mu \mathrm{g}$.$) ,$ streptomycin (25 $\mu \mathrm{g}$.$) , neomycin (10 \mu \mathrm{g}$.$) , kanamycin$ (30 $\mu \mathrm{g}$.$) , chloramphenicol (25 \mu \mathrm{g}$.), and tetracycline $(25 \mu \mathrm{g}$.$) . It was sensitive to colistin sulphate (200 \mu \mathrm{g}$.) and gentamicin $(10 \mu \mathrm{g}$.$) . It was also sensitive to$ trimethoprim $(1.25 \mu \mathrm{g}$.) though it was completely resistant to both sulphadimidine $(200 \mu \mathrm{g}$.) and sulphamethoxazole $(23.75 \mu \mathrm{g}$.). However, there was some in vitro synergistic effect between trimethoprim and sulphamethoxazole. The average zone diameter around a disc containing only trimethoprim was $23.1 \mathrm{~mm}$., but for a combination of the anti-bacterial substances the inhibition area was always larger, with an average diameter of $27 \mathrm{~mm}$.

\section{History of Outbreak}

When only limited general epidemiological information is available there is considerable difficulty in associating an uncommon enteropathogenic serotype of Esch. coli with an outbreak of infantile gastro-enteritis, despite thorough local routine laboratory investigations and the use of central specialist diagnostic facilities.

The present outbreak began at the end of December 1968 . Because Esch. coli O114 produced such a readily identifiable illness a retrospective survey suggests that by 31 March 1969, 36 children had been affected, but the organism was isolated from only 20 of these. It was cultured from a further 9 infants up to 31 July 1969. The first isolation of the organism was from a specimen of faeces dated 14 February 1969.

During December 1968 and January 1969, 11 children are considered to have been infected by the organism, which was probably brought into the hospital on 4 separate occasions. It is likely that in 3 of these instances the disease was introduced from the general community in Greater Manchester. The fourth infected child, suffering from intractable diarrhoea, was transferred from a neighbouring hospital to Booth Hall Hospital for specialist gastro-enterological care.

Many of the 7 remaining children were suffering initially from respiratory tract infections, but their illnesses gradually changed to the insidious, chronic gastro-enteritis characteristically produced by Esch. coli $\mathrm{O} 114$ in this outbreak. Thus, at this time, a respiratory pathogen was primarily sought. Further, a viral influenza epidemic was expected, while an infection with Mycoplasma pneumoniae had been diagnosed in 2 older children. The specific cases occurred sporadically over 6 weeks, and involved 3 separate infant medical wards. In contrast, there was no cross-infection with $S h$. sonnei or other recognized enteropathogenic Esch. 


\section{Outbreak of Infantile Gastro-enteritis Caused by Escherichia coli 0114}

coli serotypes among babies who were being nursed concurrently in the same cubicalized buildings.

In February, 8 cases of Esch. coli 0114 gastroenteritis occurred in two waves, five days apart, on a previously unaffected special surgical unit housing very debilitated neonates. Hence, specimens of Esch. coli were at once sent to the Salmonella Reference Laboratory who identified inter alia both Esch. coli $\mathrm{O} 114$ and $\mathrm{O} 44$ (see above). No conclusions could, therefore, be drawn, for while either might have been a pathogen, they could equally have represented part of the indigenous bland hospital flora. None the less, all the involved wards were closed for new patients and for disinfection.

At the end of March before any fresh infant medical cases had been accepted by the hospital, 3 patients were readmitted. All were well at the time of their initial discharge, but on their return they were suffering from infantile diarrhoea. Cultures submitted to the Salmonella Reference Laboratory yielded a pure growth of Esch. coli O114 from 2 of these children. It was concluded, therefore, that this organism was the probable cause of the peculiar gastro-enteritis, but no deductions could be made whether it was confined to the hospital or was more widespread in the community.

Early in April it was unofficially learnt that other hospitals in Greater Manchester were encountering gastro-enteritis of similar type. Their patients had no connexion with Booth Hall. Cultures were sent from some of these children to the Salmonella Reference Laboratory which confirmed the presence of Esch. coli O114 Between April and July 1969, 91 of the 124 cases of Esch. coli O114 infantile gastroenteritis reported to the Epidemiological Reference Laboratory of the Public Health Laboratory Service originated in north-western England. Thus, the Booth Hall outbreak consisted merely of part of a wide community experience.

Between the beginning of May and the end of July 1969, Esch. coli O114 was brought into hospital by 9 patients with gastro-enteritis.

At the close of the study cases were still being admitted from domiciliary practice and from other institutions, but the recognition of the aetiological role of Esch. coli O114 and the concomitant ability of the local laboratory to identify this serotype, both in cases and in carriers, successfully reduced the rate of cross-infection within the hospital.

\section{Discussion}

The disease we observed was unusual in its severity, and its course was reminiscent of the Aberdeen epidemic of 1947 caused by Esch. coli 0111 (Smith, 1955).
In recent years such outbreaks have been uncommon in this country and gastro-enteritis is seen as a rapidly developing illness which may require urgent supportive measures to readjust the patient's water and electrolyte balance. These corrections can usually be performed without difficulty, and the baby is able to return quickly, by way of regrading of feeds, to his routine formula. Pari passu, there is an abatement in the child's symptoms. In a few fatal cases death occurs while the infant is on his way to hospital or in the immediate resuscitative stages.

In contrast, our data show that the infantile diarrhoea caused by Esch. coli $\mathrm{O} 114$ was more insidious in starting, had a prolonged course, and a high mortality that occurred late in the illness. This was associated with gastro-intestinal haemorrhage, jaundice, and oedema. The presence of other congenital and acquired debilitating conditions, however, predisposed to a fatal outcome.

On admission to hospital, children suffering from Esch. coli $\mathrm{O} 114$ gastro-enteritis showed less disturbance of their electrolyte balance than infants with more typical forms of the disease. None the less, these children were severely ill, suggesting that the conventional blood chemistry parameters were not measuring the extent of the baby's cellular metabolic inbalance, either on admission or during their illness. Support for the hypothesis that there was widespread derangement of function was the evidence of parenchymal liver damage seen early in the disease. Simple calorie starvation could not account for this if water and electrolyte balance was restored. Our children with Esch. coli $\mathrm{O} 114$ gastroenteritis were receiving a carefully calculated and adequate diet throughout their illness. Septicaemia was never shown.

It seemed, therefore, that Esch. coli $\mathrm{O} 114$ may have produced some toxic product with a widespread bodily effect.

The primary site of action of Esch. coli 0114 could be the intracellular carbohydrate-splitting enzymes of the small intestinal mucosa, or the transport mechanism involved in carrying sugars and amino acids across cell membranes, for at first the children appeared to be intolerant of any carbohydrate. Amino acid solutions, however, were equally badly tolerated, but the earliest sign of recovery was the acceptance of these together with fructose. Lactose was especially difficult to assimilate and low lactose formulae had to be continued for long periods. In the recovery stages our attempts to perform lactose tolerance tests were unsuccessful.

Gentamicin and colistin sulphate appeared to have some effect in reducing the mortality, but no 
controlled trial was undertaken. Valman and Wilmers (1969), who also used gentamicin, only reported one death, but their outbreak of gastroenteritis caused by Esch. coli 0114 took place in the summer. In our experience, infantile gastro-enteritis, in general, is exacerbated by respiratory illness, and such diseases were widespread in the community during the winter months when we experienced our low recovery rate. In the late spring and summer we had only a single fatality.

Complete information is not available about the effect of antibiotics on the carriage of Esch. coli O114, but several patients remained excretors after prolonged courses of both gentamicin and colistin sulphate, singly and in combination. Our observations, therefore, differ from those of Valman and Wilmers who infer that gentamicin alone prevented the emergence of the carrier state. However, these workers gave their gentamicin orally, whereas we gave it intramuscularly. The colistin sulphate was usually given orally. Several children remained excretors even though they were prescribed both antibiotics directly after the isolation of Esch. coli 0114 from their admission faecal sample. Hence, the failure of specific treatment in preventing faecal carriage in these cases was not due to delay in giving the drugs. It is possible, however, that the prescription of antibiotics to which the organism was resistant was harmful. Thus, a child was discharged home as a carrier of Esch. coli $\mathrm{O} 114$ after a long illness during which he had been treated, inter alia, with specific antibiotics and freeze-dried plasma infusions: 61 days after the child was given his last blood-product unit he returned to hospital with a severe attack of hepatitis and lapsed into coma. The serum was positive for Au-SH antigen. Esch. coli O114 was not isolated from the child's stools on admission or on several subsequent occasions. He was given neomycin (to which Esch. coli $\mathrm{O} 114$ is resistant), steroids, and a high calorie diet and his level of consciousness became normal. However, the child collapsed suddenly in a state of profound shock and died. The liver disease was confirmed at necropsy, but in addition the entire length of the child's bowel was grossly distended with watery fluid, which on aerobic culture yielded a pure growth of Esch. coli O114. Cross-infection with the organism is unlikely in this instance, and it is suggested that the neomycin might have greatly reduced the normal flora in the child's bowel and left an ecological vacuum. In this, any small numbers of resistant Esch. coli $\mathrm{O} 114$ that remained from the baby's previous illness could multiply and cause very acute disease. Thus, the widespread use of antibiotics in infantile gastro-enteritis, where the sensitivity and identity of the causative organism is not known, may have occasional serious consequences, in addition to encouraging the general emergence of antibiotic-resistant bacteria.

Unfortunately, accepted pathogenic bacteria are isolated from only a minority of all children suffering from infantile diarrhoea, though in the severest cases a recognized agent is frequently found. At Booth Hall Hospital in 1968 only 82 such organisms were isolated from 250 children with gastro-enteritis. The yield of viruses has also been small, for in the period 1962-64 only 15 viruses were grown from 399 children in this hospital suffering from the disease (Holzel et al., 1965). Therefore, about two-thirds of the children admitted with gastroenteritis are discharged without any microbial cause for their illness being discovered.

The children from whom no recognized pathogenic organisms are isolated are a major hazard to babies nearby. If another child acquires their pathogen and develops disease there is no routine method of determining the origin of the infection or defining its nature. Hence, no rational control or treatment measures can be instituted. In the present outbreak it was only the unusual course of the disease that began to suggest that it was caused by a single distinctive agent. Among the 17 children who were affected by Esch. coli 0114 on the 3 medical wards as a result of probable cross-infection between December 1968 and March 1969, 8 were found while they were still in-patients, but the other 9 became ill with gastro-enteritis after they had been discharged on the completion of treatment for their primary disease. These data suggest that any child who develops gastro-enteritis during his stay in hospital or shortly after his discharge from any institution should be completely investigated to determine the bacteriological aetiology of his disease. Such investigations may show the beginnings of an outbreak caused by a little known pathogen that possesses the power of spreading.

Likewise, if no pathogenic organism is isolated by routine methods from a child dying or seriously ill with gastro-enteritis, then here too an additional full microbiological search should be made for less commonly accepted causes.

The significance of these less commonly isolated pathogenic organisms is often very difficult to evaluate and a knowledge of the indigenous ward flora is vital in interpreting the possibility of crossinfection. If it is reasonably certainly established, however, that such an agent has been identified, then this information should be immediately notified to the central and local public health authorities, 
who should be responsible for disseminating the findings to all the appropriate agencies in the field.

We would like to thank Dr. D. I. K. Evans and Dr. G. C. Turner for their help in investigating the blood coagulation and the $\mathrm{Au}-\mathrm{SH}$ antigen problems of some of these children. We are grateful to the Epidemiological Research Laboratory of the Public Health Laboratory Service for access to their records.

\section{REFERENCES}

British Medical fournal (1969). Acute infective gastroenteritis. (Leading article), 2, 263.

(1970). Gastroenteritis in children. (Note.) 2, 58.

Charter, R. E. (1956). Escherichia coli type O.114 isolated from infantile diarrhoea and calf scours. Fournal of Pathology and Bacteriology, 72, 33.

Cruickshank, R. (1965). Medical Microbiology, 11th ed., p. 497 and 912. Livingstone, Edinburgh.

Holzel, A., Parker, L., Patterson, W. H., Cartmel, D., White, L. L. R., Purdy, R., Thompson, K. M., and Tobin, J. O'H. (1965). Virus isolations from throats of children admitted to hospital with respiratory and other diseases, Manchester, 19624. British Medical fournal, 1, 614.

Jacobs, S. I. (1969). In Report on Gastroenteritis, p. $25 . \quad$ Ed. by F. N. Marshall. Department of Health and Social Security, London.

Kraybill, W. H., and Crawford, Y. E. (1965). A selective medium and color test for Mycoplasma pneumoniae. Proceedings of the Society for Experimental Biology and Medicine, 118, 965.

Lancet (1969). Gastroenteritis at Booth Hall Children's Hospital, Manchester. (Note.) 1, 843.

Linzenmeier, G. (1960). Zur Diagnostik von E. coli 114 aus Stühlen dyspepsiekranker Säuglinge. Zentralblatt für Bakteriologie, Parasitenkunde, Infektionskrankheiten und Hygiene. 1. Abteil Originale, 177, 435.

Rogers, K. B., and Cracknell, V. M. (1956). Epidemic infantile gastroenteritis due to Escherichia coli type O114. Fournal of Pathology and Bacteriology, 72, 27.

Smith, J. (1955). The Aetiology of Epidemic Infantile Gastroenteritis. Royal College of Physicians, Edinburgh.

Valman, H. B., and Wilmers, M. J. (1969). Use of antibiotics in acute gastroenteritis among infants in hospital. Lancet, 1, 1122.

Correspondence to Dr. S. I. Jacobs, Department of Pathology, St. James's Hospital, Leeds, LS9 7TF. 